ISSN : ISSN 2442-4986

An-Nadaa: Jurnal Kesehatan Masyarakat, 7 (2) Desember 2020 : 139-145 https://ojs.uniska-bjm.ac.id/index.php/ANN/article/view/3547

\title{
HUBUNGAN KARAKTERISTIK DAN STRES KERJA PERAWAT TERHADAP BURNOUT SYNDROME PADA PERAWAT PELAKSANA DI IGD DAN ICU RSUD RATU ZALECHA MARTAPURA
}

\author{
RELATIONSHIP OF CHARACTERISTICS AND WORK STRESS OF NURSES TO \\ BURNOUT SYNDROME IN IMPLEMENTING NURSES IN IGD AND ICU RSUD \\ RATU ZALECHA MARTAPURA
}

\author{
Evi Risa Mariana ${ }^{1 *}$, Suroto $^{2}$, Nanda Fajar Rezki ${ }^{3}$ \\ 1,2,3 Poltekkes Banjarmasin Jurusan Keperawatan \\ Jl. HM Cokrokusumo No 3A Kelurahan Sei Besar Banjarbaru Kalimantan Selatan. Indonesia \\ *Email: mevirisa@gmail.com
}

\begin{abstract}
The survey results from PPNI in 2006, approximately 50.9\% of nurses whose working in 4 provinces in Indonesia experienced work stress, often dizzy, exhausted, unable to rest because the workload is too high and time-consuming, low salary without suffice incentives. This, if it is not immediately handled by the hospital, will drain the stamina and emotions of nurses, and also contribute to sick that can cause pressure that makes nurses experiencing burnout or work surfeited. This study is purposed to determine the correlation between the characteristics and work stress of nurses on burnout syndrome on nurses in emergency room and intensive care unit Ratu Zalecha Martapura. The method that used in this study is non-experimental quantitative, with population of 39 nurses and using total sampling technique. The data were collected by using questionnaire. This study used the Chi-Square test. The results to be showed that there was no correlation between the characteristics and stress of nurse's work on burnout syndrome on the nurses in Emergency Room and Intensive Care Unit Ratu Zalecha Martapura with p-value 1,000 for age, 0,490 for education level and 0,465 for working period and 0,682 for work stress. Based on the result of the study, the researcher recommend are expected to maintain good communication and attitude with their bosses and colleagues so as to create a comfortable atmosphere, reduce stressor and boredom in work and stress as motivation in work.
\end{abstract}

Keywords $\quad$ : Characteristics; Nurses; Stress; Burnout.

\begin{abstract}
ABSTRAK
Hasil survei dari PPNI tahun 2006, sekitar 50,9\% perawat yang bekerja di 4 propinsi di Indonesia mengalami stres kerja, sering pusing, lelah, tidak bisa beristirahat karena beban kerja terlalu tinggi dan menyita waktu, gaji rendah tanpa insentif memadai. Hal ini, apabila tidak segera diatasi oleh pihak rumah sakit, maka akan menguras stamina dan emosi perawat, serta menimbulkan tekanan yang mengakibatkan perawat mengalami burnout atau kejenuhan kerja. Penelitian ini bertujuan untuk mengetahui hubungan antara karakteristik dan stress kerja perawat terhadap burnout syndrome pada perawat pelaksana di IGD dan ICU RSUD Ratu Zalecha Martapura. Metode yang digunakan yaitu kuantitatif non-eksperimental, dengan populasi sebanyak 39 perawat dan menggunakan teknik total sampling. Pengambilan data dilakukan dengan menggunakan kuesioner. Penelitian ini menggunakan uji Chi-Square. Hasil uji Chi-Square menunjukkan bahwa tidak terdapat hubungan antara karakteristik dan stress kerja perawat terhadap burnout syndrome pada perawat pelaksana di IGD dan ICU RSUD Ratu Zalecha Martapura dengan nilai p-value 1,000 untuk usia, 0,490 untuk tingkat pendidikan dan 0,465 untuk lama kerja serta 0,682 untuk stres kerja. Berdasarkan hasil penelitian tersebut, maka peneliti merekomendasikan agar perawat pelaksana khususnya ruang IGD dan ICU diharapkan untuk mempertahankan komunikasi dan sikap yang baik dengan atasan maupun rekan kerja sehingga mampu menciptakan suasana yang nyaman, mengurangi stressor dan kebosanan dalam bekerja serta menjadikan stres sebagai motivasi dalam bekerja.
\end{abstract}

Kata Kunci $\quad$ : Karakteristik; Perawat; Stres; Burnout. 


\section{PENDAHULUAN}

Menurut Keputusan Menteri Kesehatan Republik Indonesia No. 304/MENKES/PER/III/2010 bahwa rumah sakit adalah institusi pelayanan kesehatan yang menyelenggarakan pelayanan kesehatan perorangan secara paripurna yang menyediakan pelayanan rawat inap, rawat jalan, dan gawat darurat. Instalasi Gawat Darurat (IGD) merupakan unit penting dalam operasional suatu rumah sakit yaitu sebagai pintu masuk bagi setiap pelayanan yang beroperasi selama 24 jam. Tuntutan beban kerja yang tingi dalam lingkungan kegawat daruratan menyebabkan perawat IGD berisiko terhadap terjadinya stress yang nantinya akan menyebabkan burnout syndrome) (1)

Beban kerja dan tingkat stress yang tinggi tidak hanya terjadi di IGD, tetapi juga terjadi di ICU. Menurut Menteri Kesehatan Nomer: 1778/MenKes/SK/XII/2010 menyatakan bahwa ICU merupakan suatu bagian dari rumah sakit dengan staf dan perlengkapan khusus. Hal ini di tunjukkan untuk mengobservasi dan memberikan terapi pasien yang menderita penyakit, cidera atau yang mengancam nyawa, sehingga perawat ICU dituntut untuk memiliki kemampuan khusus dibanding dengan perawat di unit lain.

Perawat merupakan salah satu profesi atau pekerjaan yang dapat memberikan banyak manfaat bagi orang lain. Harley (2) menjelaskan seorang perawat yaitu pada dasarnya seseorang yang berperan dalam merawat atau memelihara, membantu dan melindungi seseorang karena sakit, terluka dan proses penuaan. Sedangkan dilihat dari sisi intensitas interaksi dengan pasien, perawat merupakan tenaga kesehatan yang paling tinggi interaksinya dengan pasien (3).

Pada kenyataannya tidak semua perawat mampu menjalankan tugas dan fungsinya dengan baik, sering kali mereka mengalami kelelahan mental dan emosional akibat tugasnya yang harus selalu siap memberikan pelayanan yang maksimal bagi orang lain. Hal ini, apabila tidak segera diatasi oleh pihak rumah sakit, maka akan menguras stamina dan emosi perawat, serta menimbulkan tekanan yang mengakibatkan perawat mengalami burnout atau kejenuhan kerja. Penelitian yang dilakukan oleh Moreira et al (4) pada perawat yang bekerja pada rumah sakit besar di Brasil Selatan menunjukkan bahwa prevalensi perawat yang mengalami burnout sebanyak 35,7\% dari 151 responden. Al-Turki et al (5) juga melakukan penelitian terkait burnout syndrome pada perawat yang berjudul "Burnout Syndrome among Multinational Nurses Working in Saudi Arabia" menunjukkan hasil $89 \%$ staf perawat mengalami emotional exhaustion, $42 \%$ mengalami depersonalization, dan $71,5 \%$ mengalami low personal accomplishment. Berdasarkan hasil survei dari PPNI tahun 2006, sekitar 50,9\% perawat yang bekerja di 4 propinsi di Indonesia mengalami stres kerja, sering pusing, lelah, tidak bisa beristirahat karena beban kerja terlalu tinggi dan menyita waktu, gaji rendah tanpa insentif memadai (6)

Penelitian yang dilakukan oleh Ana Damayanti (7) tentang faktor yang berhubungan dengan kejadian burnout syndrome pada perawat IGD dan ICU RSUD Ulin Banjarmasin. Penelitian terhadap 70 responden perawat IGD dan ICU menunjukkan mayoritas kejadian burnout responden yang terbanyak adalah burnout rendah sebanyak 39 orang atau sebesar $55,7 \%$. Studi Pendahuluan yang dilakukan oleh peneliti pada tanggal 04 Desember 2017 di dua ruangan yaitu IGD dan ICU. Didapatkan jumlah perawat pelaksana di IGD sebanyak 23 orang dan perawat di ICU sebanyak 16 orang. Dari hasil wawancara peneliti dengan kepala ruang IGD beliau mengatakan ada beberapa perawat yang pernah mengeluh kepada beliau bahwa perawat tersebut ada keinginan untuk pindah ruangan karena beberapa perawat mengatakan sudah terlalu lama bekerja di IGD. Kinerja perawat di IGD menurut beliau sudah baik karena perawat menjalankan prosedur sesuai SOP.

Menurut Maslach, 2001 dalam Nursalam (8) menyatakan faktor-faktor yang mempengaruhi burnout syndrome dibagi menjadi 2 faktor yaitu faktor personal dan faktor lingkungan, Faktor personal terdiri dari kepribadian, harapan, demografi atau karakteristik (usia, tingkat pendidikan, masa kerja), control focus, tingkat efisiensi, sedangkan untuk faktor lingkungan yaitu terdiri dari beban kerja, stress kerja, penghargaan, control kepemilikan, keadilan dan nilai. Apabila burnout syndrome pada perawat ini tidak diatasi secara tepat maka akan berdampak pada kinerja perawat yang nantinya akan menyebabkan kualitas pelayanan rumah sakit menurun.

Peneliti melakukan wawancara dengan 5 perawat yang bekerja di IGD, 3 dari 5 perawat tersebut mengatakan sudah bosan karena terlalu lama bekerja di IGD, sedangkan 2 perawat lainnya 
mengatakan beban kerja di IGD sangat tinggi. Peneliti juga mewawancarai kepala ruang ICU, beliau mengatakan ada sekitar 3-4 orang yang pernah mengeluh ingin pindah ruangan karena jenuh dengan rutinitas pekerjaan di ICU dan beben kerja yang sangat fluktuatif. Kinerja perawat di ICU baik, namun tergantung individu masing-masing kadang ada perawat yang rajin dan ada juga yang tidak. Beliau juga mengatakan ada sekitar 3 kali pelatihan ditahun 2017 dan diikuti oleh beberapa orang perawat ICU.

Peneliti juga melakukan wawancara dengan 5 orang perawat ICU. 5 perawat mengatakan ada persaan bosan dan lelah selama bekerja di ICU. 3 perawat beralasan karena beban kerja yang tinggi dan sudah terlalu lama bekerja di ICU sehingga ada keinginan untuk pindah ruangan. 2 perawat beralasan karena rutinitas dan suasana lingkungan yang monoton. 4 perawat ditahun 2017 telah mengikuti 1-2 kali pelatihan.

Rumusan masalah dalam penelitian ini berdasarkan latar belakang yang telah diuraikan di atas adalah "Apakah ada hubungan karakteristik dan stress kerja perawat terhadap burnout syndrome pada perawat pelaksana di ruang IGD dan ICU RSUD Ratu Zalecha Martapura.

\section{BAHAN DAN METODE}

Jenis penelitian ini menggunakan penelitian kuantitatif, dengan jenis penelitian correlational yaitu penelitian yang bertujuan untuk menentukan ada atau tidak hubungan antara karakteristik (usia, tingkat pendidikan, dan lama kerja) perawat dengan kejadian burnout dan stres kerja dengan kejadian burnout perawat IGD dan ICU RSUD Ratu Zalecha Martapura. Populasi dalam penelitian ini adalah semua perawat yang bertugas di IGD dan ICU RSUD Ratu Zalecha Martapura yang berjumlah 39 perawat terdiri dari 23 perawat IGD dan 16 perawat ICU, metode pengambilan sampel yang digunakan yaitu total sampling. Pengumpulan data dilakukan secara primer dan sekunder. Data primer dikumpulkan melalui kuesioner yang langsung diberikan kepada responden, yaitu perawat pelaksana IGD dan ICU di RSUD Ratu Zalecha Martapura. Sedangkan data sekunder diperoleh dari kepala ruang IGD dan ICU RSUD Ratu Zalecha Martapura. Instrument pengumpulan data yang digunakan pada penelitian ini adalah kuesioner. Analisis data yaitu analisa univariat dan analisa Bivariat menggunakan uji Chi-
Square, karena tabel $2 \times 2$ dan tidak ada nilai $\mathrm{E}<5$ sehingga peneliti membaca $p$-value pada kolom Continuity Correction[3], namun apabila tabel $2 \times 2$ terdapat nilai $\mathrm{E}>5$ sehingga peneliti membaca $p$ value pada kolom Fisher's Exact Test. penggunaan rumus ini adalah untuk mengetahui hubungan antara satu variabel independen dan satu variabel dependen

\section{HASIL DAN PEMBAHASAN}

\section{Hasil Penelitian}

Tabel 1 Distribusi Frekuensi Karakteristik Responden Berdasarkan Usia perawat, pendidikan, Lama Kerja, strees kerja dan Kejadian Burnout Syndrome pada perawat IGD dan ICU RSUD Ratu Zalecha Martapura tahun 2018

\begin{tabular}{lll}
\hline Variabel & $\mathbf{n}$ & $\%$ \\
\hline Usia & & \\
Tua ( $\geq 30$ tahun) & 27 & 69,23 \\
$\begin{array}{l}\text { Muda (<30 tahun) } \\
\text { Pendidikan }\end{array}$ & 12 & 30,77 \\
SPK & 2 & 5,12 \\
Perguruan Tinggi & 37 & 94,88 \\
Lama Kerja & & \\
Lama ( $\geq 5$ tahun) & 29 & 74,35 \\
Muda (<5 tahun) & 10 & 25,65 \\
Stress Kerja & & \\
Sedang (51\%-75\%) & 7 & 17,95 \\
Ringan (25\%-50\%) & 32 & 82,05 \\
Kejadian $\quad$ Burnout & & \\
Syndrome & & \\
Tinggi $(Z \geq 0)$ & 18 & 46,15 \\
Rendah $(Z<0)$ & 21 & 53,95 \\
Jumlah & 39 & 100 \\
\hline
\end{tabular}

Berdasarkan tabel 1 diatas menunjukkan mayoritas usia responden terbanyak yaitu Tua ( $\geq 30$ tahun) sebanyak 27 orang $(69,23 \%)$. Variabel pendidikan menunjukkan mayoritas tingkat pendidikan responden terbanyak yaitu tingkat pendidikan perguruan tinggi sebanyak 37 orang $(94,88 \%)$.Variabel lama kerja, menunjukkan mayoritas lama kerja responden terbanyak yaitu lama kerja yang lama sebanyak 29 orang $(74,35 \%)$. Variabel stres kerja responden yang terbanyak adalah sedang (51\%-75\%) yaitu sebanyak 32 orang $(82,05 \%)$. Sedangkan variabel Burnout Syndrome menunjukkan mayoritas kejadian burnout syndrome responden yang 
terbanyak adalah rendah $(Z<0)$ yaitu sebanyak 21 orang $(53,95 \%)$

\section{Hubungan Karakteristik Perawat berhubungan dengan Burnout pada perawat IGD dan ICU RSUD Ratu Zalecha Martapura tahun 2018}

1. Hubungan usia terhadap burnout syndrome perawat

Berdasarkan hasil uji statistik $\left(x^{2}\right)$ diperoleh $p$-value pada Continuity Correction adalah 1,000 dengan demikian $p$-value $(1,000)>\alpha \quad(0,05)$ sehingga Ho diterima yang berarti tidak ada hubungan antara usia dengan kejadian burnout pada perawat IGD dan ICU RSUD Ratu Zalecha Martapura

2. Hubungan tingkat pendidikan terhadap burnout syndrome perawat

Berdasarkan hasil uji statistik $\left(x^{2}\right)$ diperoleh p-value pada Fisher's Exact adalah 0,490 dengan demikian $p$-value $(0,490)>\alpha(0,05)$ sehingga Ho diterima yang berarti tidak ada hubungan antara tingkat pendidikan dengan kejadian burnout pada perawat IGD dan ICU RSUD Ratu Zalecha Martapura

3. Hubungan lama kerja terhadap burnout syndrome perawat

Berdasarkan hasil uji statistik $\left(x^{2}\right)$ diperoleh p-value pada Fisher's Exact adalah 0,465 dengan demikian $p$-value $(0,465)>\alpha(0,05)$ sehingga Ho diterima yang berarti tidak ada hubungan antara lama kerja dengan kejadian burnout pada perawat IGD dan ICU RSUD Ratu Zalecha Martapura

Hubungan Stres Kerja Perawat berhubungan dengan Burnout pada perawat IGD dan ICU RSUD Ratu Zalecha Martapura tahun 2018

Berdasarkan hasil uji statistik $\left(x^{2}\right)$ diperoleh $p$ value pada Fisher's Exact adalah 0,682 dengan demikian $p$-value $(0,682)>\alpha(0,05)$ sehingga Ho diterima yang berarti tidak ada hubungan antara stress kerja dengan kejadian burnout pada perawat IGD dan ICU RSUD Ratu Zalecha Martapura.

\section{PEMBAHASAN}

Identifikasi karakteristik perawat IGD dan ICU RSUD Ratu Zalecha Martapura

\section{Berdasarkan usia}

Pada tabel 1 terlihat bahwa distribusi frekuensi usia perawat IGD dan ICU mayoritas berada pada usia tua ( $\geq 30$ tahun) sebanyak 27 orang $(69,23 \%)$ dan usia muda (< 30 tahun) sebanyak 12 (30,77\%). Berdasarkan statistik ini dapat disimpulkan lebih dari separu populasi perawat IGD dan ICU berusia lebih dari 30 tahun.

2. Berdasarkan tingkat pendidikan

Pada Tabel 1 terlihat bahwa distribusi frekuensi tingkat pendidikanperawat IGD dan ICU mayoritas yaitu perguruan tinggi sebanyak 37 orang $(94,88 \%)$, sedangkan SPK hanya sebanyak 2 orang (5,12\%). Dari statistik ini dapat disimpulkan bahwa tingkat pendidikan perguruan tinggi mendominasi di IGD dan ICU Ratu Zalecha Martapura.

3. Berdasarkan lama kerja

Pada tabel 1 terlihat bahwa distribusi frekuensi lama kerja perawat IGD dan ICU mayoritas lama kerja yang lama ( $\geq 5$ tahun) sebanyak 29 orang $(74,35 \%)$ dan lama kerja yang baru (< 5 tahun) sebanyak 10 (25,65\%). Berdasarkan statistik ini dapat disimpulkan lebih dari separu pupulasi perawat IGD dan ICU memili lama kerja yang lama $\geq 5$ tahun.

\section{Identifikasi stres kerja perawat IGD dan ICU RSUD Ratu Zalecha Martapura}

Pada tabel 1 terlihat bahwa distribusi frekuensi stres kerja perawat IGD dan ICU mayoritas mengalamistres kerja ringanyaitu sebanyak 32 orang $(82,05 \%)$. Sedangkan sebanyak 7 orang $(17,95 \%)$ responden mengalami stres kerja sedang. Berdasarkan statistik deskriptif dapat disimpulkan bahwa yang lebih dari separuh populasi perawat IGD dan ICU yang diteliti mengalami stres kerja yang ringan. Stres merupakan kondisi ketegangan yang berpengaruh terhadap emosi, jalan pikiran dan kondisi fisik seseorang. Stres yang tidak diatasi dengan baik biasanya akan berakibat pada ketidakmampuan seseorang berinteraksi secara positif dengan lingkungannya, baik dalam arti lingkungan pekerjaan maupun diluarnya. Artinya karyawan yang bersangkutan akan menghadapi berbagai gejala negative yang pada gilirannya berpengaruh pada prestasi kerja Perawat yang mengalami stres menjadi nervous dan merasakan kekuatiran kronis sehingga mereka sering marahmarah, agresif, tidak dapat relaks atau 
memperlihatkan sikap yang tidak kooperatif. Stres yang berlanjut dan tidak teratasi nantinya dapat mengakibatkan burnout syndrome (9).

Hasil penelitian menunjukan bahwa stress kerja perawat IGD dan ICU yang menjadi responden, sebanyak 32 orang $(82,05 \%)$ responden mengalami stres kerja yang ringan. Hal ini didukung dari hasil rekapitulasi data jawaban sebagian besar responden pada kuesioner stres kerja mendapat skor terendah (1 = tidak pernah) yaitu pada pertanyaan nomor 14 yaitu merasa tertekan dengan pekerjaan, nomor 15 yaitu menyalahkan diri sendiri, nomor 16 yaitu merasa tidak cocok dengan pekerjaan, nomor 30 yaitu keiniginan meninggalkan pekerjaan, nomor 34 yaitu mudah marah tanpa sebab yang berarti, dan nomor 35 yaitu merasa tidak suka dengan pekerjaan. Hasil rekapitulasi data tersebut peneliti menyimpulkan bahwa lebih dari separuh populasi perawat IGD dan ICU tidak pernah merasakan hal tersebut.

\section{Identifikasi burnout syndrome perawat IGD dan ICU RSUD Ratu Zalecha Martapura}

Tabel 1 terlihat bahwa distribusi frekuensi kejadian burnout perawat IGD dan ICU mayoritas burnout rendah yaitu sebanyak 21 orang (53,95\%).Sedangkan sebanyak 18 orang (46,15\%) responden yang memilikiburnout tinggi. Berdasarkan statistik deskriptif dapat disimpulkan bahwa yang lebih dari separuh populasi perawat IGD dan ICU yang diteliti mengalami burnout rendah. Hasil penelitian menunjukkan bahwa kejadian burnout perawat IGD dan ICU yang menjadi responden, sebanyak 21 orang (53,95\%) mengalami kejadian burnout rendah. Hal ini didukung oleh hasil rekapitulasi data jawaban sebagian besar responden pada kuesioner Burnout Syndrome mendapatkan skor terendah $(0=$ tidak pernah) yaitu pada pertanyaan nomor 6 yaitu saya merasa frustasi dengan pekerjaan saya selama menjalani praktik profesi, nomor 10 yaitu saya merasa memperlakukan pasien sebagai objek yang tidak perlu dipahami secara personal (yang penting saya bisa mendapatkan kompetensi), dan nomor 13 yaitu saya tidak perduli dengan apa yang dialami pasien dan hanya menjalankan tugas saya seperlunya saja.Berdasarkan hasil rekapitulasi data tersebut peneliti menyimpulkan bahwa lebih dari separuh populasi perawat IGD dan ICU tidak pernah merasakan hal tersebut.

Hubungan Karakteristik dengan burnout syndrome pada perawat IGD dan ICU RSUD Ratu Zalecha Martapura

Hasil uji statistik $\left(x^{2}\right)$ diperoleh $p$-value pada Continuity Correction adalah 1,000 dengan demikian $p$-value $(1,000)>\alpha(0,05)$ sehingga Ho diterima yang berarti tidak ada hubungan antara usia dengan kejadian burnout pada perawat IGD dan ICU RSUD Ratu Zalecha Martapura. Hal ini didukung oleh penelitian yang dilakukan oleh Larasati dan Paramita (2013) yang berjudul "Tingkat Burnout Ditinjau dari Karakteristik Demografis (Usia, Jenis Kelamin dan Masa Kerja) Guru SDN Inklusi di Surabaya" yang menunjukkan hasil bahwa tidak ada hubungan yang signifikan antara usia (pvalue $=0,760$ ) terhadap burnout syndrome. Oleh karena itu peneliti menyimpulkan bahwa usia tidak menunjukkan perbedaan terhadap keinginan untukburnout perawat IGD dan ICU, karena usia tua maupun muda samasama menunjukan kejadian burnout rendah walaupun usia muda mengalami burnout rendah dan tinggi yang berimbang. Hal ini karena para pekerja pemberi pelayanan di usia muda dipenuhi dengan harapan yang tidak realistik, jika dibandingkan dengan mereka yang berusia lebih tua. Seiring dengan pertambahan usia pada umumnya individu menjadi lebih matang, lebih stabil, lebih teguh sehingga memiliki pandangan yang lebih realistis (10). Selain itu dikarenakan faktor lain, pada usia tua lebih dari 30 tahun mayoritas sudah merasa nyaman terhadap pekerjaan mereka sehingga tidak ingin kembali beradaptasi terhadap lingkungan baru, serta ingin menghabiskan masa kerjanya/ pensiun di satu tempatsaja. jadi untuk perawat dengan usia tua tidak merasa jenuh dan tidak ada keinginan untuk meninggalkan pekerjaan, sedangkan usia muda memiliki harapan yang tinggi namun terkadang tidak sesuai dengan kenyataan .

Hasil uji statistik $\left(x^{2}\right)$ diperoleh $p$-value pada Fisher's Exact Test adalah 0,490 dengan demikian $p$ value $(0,490)>\alpha(0,05)$ sehingga Ho diterima yang berarti tidak ada hubungan antara tingkat pendidikan dengan kejadian burnout pada perawat IGD dan ICU RSUD Ratu Zalecha Martapura. Hal ini bertentangan dengan hasil penelitian 
menyebutkan bahwa seseorang dengan pendidikan perguruan tinggi paling berisiko mengalami Burnout syndrome dibandingkan tingkat pendidikan lainnya. Profesional yang berpendidikan tinggi memiliki harapan atau aspirasi yang idealis, sehingga ketika dihadapkan pada kesenjangan antara aspirasi dan kenyataan maka muncul kegelisahan dan kekecewaan yang dapat menimbulkan Burnout syndrome. Oleh karena itu peneliti menyimpulkan bahwa tingkat pendidikan tidak menunjukkan perbedaan yang signifikan untuk terjadinya keinginanburnout padaperawat IGD dan ICU, karena tingkat pendidikan perguruan tinggi dan SPK samasama mengalami burnout rendah.

Hasil uji statistik $\left(x^{2}\right)$ diperoleh $p$-value pada Fisher's Exact Test adalah 0,465 dengan demikian $p$ value $(0,465)>\alpha(0,05)$ sehingga Ho diterima yang berarti tidak ada hubungan lama kerja dengan kejadian burnout pada perawat IGD dan ICU RSUD Ratu Zalecha Martapura. Hal ini didukung oleh penelitian yang dilakukan oleh Larasati dan Paramita (2013) yang berjudul “Tingkat Burnout Ditinjau dari Karakteristik Demografis (Usia, Jenis Kelamin dan Masa Kerja) Guru SDN Inklusi di Surabaya" yang menunjukkan hasil bahwa tidak ada hubungan yang signifikan antara masa kerja (pvalue $=0,674)$ terhadap burnout syndrome. Oleh karena itu peneliti menyimpulkan bahwa lama kerja tidak menunjukkan perbedaan yang signifikan untuk terjadinya keinginan untukburnout perawat IGD dan ICU, karena dari hasil uji statistic tidak terdapat hubungan walaupun dari tabel tabulasi silang dapat dilihat perbedaan antara lama kerja yang lama cenderung mengalami burnout rendah dan lama kerja yang baru cenderung mengalami burnout tinggi. Hal ini dikarenakan adanya faktor lain, misalnya faktor karakteristik individu itu sendiri dimana persepsi seseorang terhadap lingkungannya berbeda-beda walaupun stimulusnya sama, sehingga masa kerja yang baru ataupun lama tergantung karakteristik individunya bagaimana mengatasi stimulus yang dijalaninya.

Hubungan stress kerja perawat dengan burnout syndrome pada perawat IGD dan ICU RSUD Ratu Zalecha Martapura
Hasil uji statistik $\left(x^{2}\right)$ diperoleh $p$-value pada Fisher's Exact Test adalah 0,682 dengan demikian $p$ value $(0,682)>\alpha(0,05)$ sehingga Ho diterima yang berarti tidak ada hubungan stres kerja dengan kejadian burnout pada perawat IGD dan ICU RSUD Ratu Zalecha Martapura. Hal ini bertentangan dengan hasil penelitian dari widodo penelitian Widodo Hariyono (12) bahwa ada hubungan yang signifikan antara stress kerja dengan kelelahan kerja perawat di Rumah Sakit Islam Yogyakarta PDHI dengan nilai taraf signifikansi 0,026 $<0,05$. Oleh karena itu peneliti menyimpulkan bahwa stres kerja tidak menunjukkan perbedaan yang signifikan untuk terjadinya keinginanburnout perawat IGD dan ICU, karena dari hasil uji statistic tidak terdapat hubungan walaupun dari tabel tabulasi silang dapat dilihat perbedaan antara stres kerja yang sedang cenderung mengalami burnout tinggi dan stres kerja yang ringan cenderung mengalami burnout rendah. Hal ini dikarenakan stres kerja yang ringan mampu membuat sesorang fokus dalam bekerja sehingga gejala burnout berkurang, sedangkan stres kerja yang tinggi membuat seseorang gelisah dan tidak tenang dalam bekerja sehingga membuat resiko burnout meningkat.

\section{KESIMPULAN DAN SARAN}

Hasil penelitian menunjukkan variabel usia dengan kejadian burnout syndrome bahwa tidak ada hubungan antara usia dengan kejadian burnout pada perawat IGD dan ICU RSUD Ratu Zalecha Martapura. Hasil uji statistik untuk variabel tingkat pendidikan dengan kejadian burnout syndrome bahwa tidak ada hubungan antara tingkat pendidikan dengan kejadian burnout pada perawat IGD dan ICU RSUD Ratu Zalecha Martapura. Hasil uji statistik untuk variabel lama kerja dengan kejadian burnout syndrome bahwa tidak ada hubungan antara lama kerja dengan kejadian burnout pada perawat IGD dan ICU RSUD Ratu Zalecha Martapura. Hasil uji statistik untuk variabel stres kerja dengan kejadian burnout syndrome bahwa tidak ada hubungan antara stres kerja dengan kejadian burnout pada perawat IGD dan ICU RSUD Ratu Zalecha Martapura. Rumah sakit. Bagi pihak RSUD Ratu Zalecha Martapura, diharapkan untuk memperhatikan stres kerja perawat terutama ruangan IGD dan ICU yang memiliki beban kerja yang tinggi dari ruangan lain, untuk meminimalkan terjadinya burnout pada 
perawat pelaksana dengan cara yaitu misalnya mengadakan kegiatan diluar rumah sakit seperti liburan 1 bulan sekali atau 2 bulan sekali.
12. Widodo. 2010. Perbedaan tingkat stress kerja antara perawat krtis dan perawat gawat darurat di RSUD Dr. Moewardi Surakarta. Skripsi

\section{DAFTAR PUSTAKA}

1. Latif Dharmahari Wibowo, 2016 Gambaran Tingkat Stres Kerja Perawat di Instalasi Gawat Darurat dan Intensive Care Unit Rumah Sakit Umum Daerah Watas Kulon Progo. Di peroleh tanggal 13 November dari http://repository.stikesayaniyk.ac.id/id/eprint/5 $\underline{83}$.

2. Robbins, et al. 2008.Perilaku Organisasi. Salemba Empat, Jakarta.

3. Sudarman, M. 2008. Sosiologi untuk Kesehatan. Jakarta: Salemba.

4. Moreira, et al. 2009. Prevalence of Burnout Syndrome in Nursing Staff In A Large Hospital in South of Brazil. Medline Journal, 25(7):1559-68.

5. Al-Turki, H.A. et al. 2010. Burnout Syndrome Among Multinational Nurses Working in Saudi Arabia. Saudi Med Journal, 31(3):313-316.

6. Dian Yunita Sari, Ni Luh Putu 2016. Hubungan Beban Kerja, Faktor Demografi, Locus of Control, dan Harga diri Terhadap Burnout Syndrome Pada Perawat Pelaksana Ruang Intermediet RSUP Sanglah. Di peroleh pada tanggal 9 November 2020

dari http://binausadabali.ejurnal.info/index.php/kes ehatan/article/view/23.

7. Damayanti, Ana 2017. Faktor Yang Berhubungan Dengan Kejadian Burnout Syndrome Pada Perawat IGD dan ICU RSUD Ulin Banjarmasin.

8. Nursalam, 2016. Metodelogi Penelitian Ilmu Keperaatan: Pendekatan Praktis Edisi 4. Jakarta : Salemba Medika.

9. Sondang P. Siagian, 2009. Kiat Meningkatkan Produktivitas Kerja. Jakarta: PT. Rineka Cipta.

10.Sutjipto. 2001. Burnout studi mengungkap psikologi dunia kerja. Semarang; GI gema Insani off set.

11. Dian Yunita Sari, Ni Luh Putu 2016. Hubungan Beban Kerja, Faktor Demografi, Locus of Control, dan Harga diri Terhadap Burnout Syndrome Pada Perawat Pelaksana Ruang Intermediet RSUP Sanglah. Di peroleh pada tanggal 9 November 2020

dari http://binausadabali.ejurnal.info/index.php/kes ehatan/article/view/23. 